Check for updates

Cite this: RSC Adv., 2019, 9, 18147

Received 17th April 2019

Accepted 16th May 2019

DOI: $10.1039 / c 9 r a 02898 f$

rsc.li/rsc-advances

\section{The effect of ISR on OFMSW during acidogenic fermentation for the production of AD precursor: kinetics and synergies}

\begin{abstract}
Abdul F. Soomro, ${ }^{\text {Z }}$ Zhe Ni, ${ }^{\text {b }}$ Li Ying (D) ${ }^{c}$ and Jianguo Liu (D) *a
Acidogenic fermentation of the organic fraction of municipal solid waste (OFMSW) and its components (food waste, paper waste) was studied in a batch percolator reactor without artificial pH adjustment. The effect of inoculum to substrate ratio on process performance, in terms of $\mathrm{pH}$, hydrolysis and volatile fatty acid (VFA) production, has been investigated. The inoculum to substrate ratio (ISR) was varied from 0 to $0.36 \mathrm{VS} / \mathrm{VS}$ and at optimized conditions for fermentation of OFMSW, with ISR $0.23, \mathrm{pH}$, hydrolysis and acidification yield were 5.5, $625 \mathrm{mg} \mathrm{sCOD} \mathrm{per} \mathrm{g} \mathrm{BD} \mathrm{VS} \mathrm{and} 408 \mathrm{mg} \mathrm{g}^{-1}$ BD VS respectively. Due to the uplift of $\mathrm{pH}$ from 4 to 5.5 because of addition of ISR, the VFA composition was dominated mostly by butyric, acetic acids and propionic acid. Kinetics regarding rate of hydrolysis and acidification were calculated and reported. A significant synergistic effect was noticed in the acidification and hydrolysis, which were 1.76 and 1.35 fold higher than individual components (paper waste and food waste) of OFMSW, respectively and approximately $70 \%$ of biodegradable solid carbon solubilized into the liquid carbon within a short retention time of $78 \mathrm{~h}$.
\end{abstract}

\section{Introduction}

The organic fraction of municipal solid waste (OFMSW) is currently one of the major interests in the research community due to its high biodegradability (BD) and its potential for environmental pollution. ${ }^{1}$ Especially in developing countries, OFMSW is characterized by a wide range of easily biodegradable organic matter which includes $37-51 \%$ carbon and $80-90 \%$ volatile solids. ${ }^{2}$ Food waste (FW) and paper waste (PW) are two major components of OFMSW, comprising a total of $c a .90 \%{ }^{3}$ Simultaneously the nature of these wastes differ to a greater extent towards acidification. While PW contains a large amount of carbohydrate, it has a high $\mathrm{C} / \mathrm{N}$ ratio which corresponds to the lack of basic raw materials for the production of amino acids for microorganisms. ${ }^{4}$ Conversely, food waste (FW) is nitrogen-rich due to the abundant availability of protein. ${ }^{5}$ Therefore, the supply of essential nitrogen element from FW can enhance the acidogenic fermentation of OFMSW. However, in municipal waste, PW and FW are always mixed.

Moreover, MSW with high organic fraction is a potential resource, if treated under controlled conditions. ${ }^{6,7}$ From this perspective, volatile fatty acids (VFA), generated via anaerobic fermentation of OFMSW, is considered as an economical and feasible technology practice, since these VFAs have a broad range

${ }^{a}$ School of Environment, Tsinghua University, Beijing, 100084, China.E-mail:jgliu@ tsinghua.edu.cn

${ }^{b}$ Beijing GeoEnviron Engineering \& Technology, Inc, Beijing 100095, China

${ }^{c}$ Key Laboratory of Clean Energy of Liaoning, College of Energy and Environment, Shenyang Aerospace University, Shenyang 110136, China of practical applications which includes methane recovery from anaerobic digestion, biological nutrient removal (BNR) in modern municipal and industrial wastewater treatment plants (WWTP), polyhydroxyalkanoates (PHA) production. ${ }^{8-10}$ The composition and concentration of these VFAs are influenced by several factors, including hydraulic retention time (HRT), $\mathrm{pH}$, initial organic load (IOL), inoculum to substrate ratio (ISR), C/N ratio, particle size and reactor modes. ${ }^{6,11-14}$

Most of the studies were reported for enhancement of VFA production through adjustment of $\mathrm{pH}$ by adding different chemicals. However, it is not economically viable at large-scale applications. Moreover, disposal of bioreactors effluent with high concentration of chemicals may lead to high cost and can have negative impacts on bacterial community. ${ }^{13}$ Some studies reported that VFAs could be efficiently produced without artificially controlling the $\mathrm{pH} .{ }^{15,16} \mathrm{The} \mathrm{pH}$ can be elevated by applying different processing methods such as ultrasonication pretreatment, ${ }^{17}$ change in temperature $45-70{ }^{\circ} \mathrm{C},{ }^{18,19}$ ISR $0.2-1$ (ref. 20) and mixed fermentation. ${ }^{21,22}$ Among all, ISR and mixed fermentation methods are recognized for their practical applicability at the large-scale for the separation of biodegradable dissolved organic matter as a renewable carbon sources for AD precursor.

ISR (microorganism) is the fundamental driver to accelerate the acidogenic process. The inoculum type and its quantity are significant factors that affect the hydrolysis and acidification pathways. ${ }^{23}$ Most of the research studies reported in the literature investigated the significance of ISR during acidogenic fermentation of FW with $\mathrm{pH}$ controlled by external means ${ }^{12,24}$ Furthermore, a wide range of ISR values were employed in the existing studies, however, it is quite complicated to compare 
different substrates and inoculum used. For example, an ISR 1 was suggested for the acidogenic fermentation of grass, ${ }^{25} 0.02$ for manure, ${ }^{26} 0.13$ for $\mathrm{FW}^{20}$ and 0.5 for mixed fermentation of excess sludge and FW. ${ }^{21}$ Several studies have been conducted for VFA production from sole FW..$^{6,11,13,21,22,27-29}$ Sole PW was used for the production of methane ${ }^{30}$ and ethanol production at a controlled $\mathrm{pH} 5 .^{31}$

However, particular organic components of OFMSW can significantly influence its behavior during anaerobic fermentation. To the best of our knowledge, no study has been conducted to compare the distinction in product characteristics from mixed OFMSW and its sole components (e.g. food waste and paper waste) during the acidogenic fermentation. The results will help to explain the effects of individual fraction of OFMSW on the acidification.

In this study, a series of ISR, namely $0.09,0.23$ and 0.36 , were applied for VFAs fermentation of mixed OFMSW in percolator reactor, with respect to the comprehensive evolution of products characteristic and their kinetics. The novel aspect of this study was to investigate mixed- and mono-fermentation from OFMSW without pH control, as well as their synergistic effects, based on sole components, were evaluated for hydrolysis and acidogenic stages, respectively. The results obtained above were used to discover the possible $\mathrm{pH}$ mechanisms and relative parameters for enhancing acidogenic fermentation of OFMSW.

\section{Materials and methods}

\subsection{Substrate \& inoculum}

A physical representative mixture of OFMSW was prepared on the basis of composition of the typical municipal solid waste (MSW) of China. ${ }^{3}$ The representative FW was prepared on the basis of the data reported by $\mathrm{Xu}$ et al., ${ }^{32}$ which were mediated over the year of investigation. Before loading into the percolator, the synthetic OFMSW was manually shredded to maintain a uniform size of $40-50 \mathrm{~mm}(\mathrm{FW})$ and $5 \times 20 \mathrm{~mm}(L \times W)$ paper pieces before being mixed. Anaerobically digested sludge under mesophilic conditions was obtained from the Dongcun waste treatment plant, Beijing, China and after natural sedimentation for 15 days was used as inoculum. Additionally, the sludge was sieved through a $2 \mathrm{~mm}$ sieve for removal of large particles. Composition and ultimate analysis are shown in Tables 1 and 2.

\subsection{Percolator reactor and experimental setup}

The laboratory scale percolation reactor consisting of a rectangular tank with a total volume of $30 \mathrm{~L}$ and working volume $20 \mathrm{~L}$, as shown in Fig. 1, was used in the study.

Table 1 Composition and characteristics of OFMSW and inoculum ${ }^{a}$

\begin{tabular}{lrrcc}
\hline Component & \multicolumn{1}{l}{ TS\% } & \multicolumn{1}{l}{ VS\% } & Dry COD & BD (VS\%) \\
\hline FW & $94.52 \pm 3.1$ & $94.52 \pm 2.9$ & $1.33 \pm 0.01$ & $72.3 \pm 4.12$ \\
PW & $96.46 \pm 2.1$ & $79.66 \pm 3.2$ & $1.008 \pm 0.053$ & $60.2 \pm 3.02$ \\
OFMSW & $27.78 \pm 1.1$ & $87.3 \pm 3.9$ & $1.175 \pm 0.04$ & $69.37 \pm 4.5$ \\
AD sludge & $6.45 \pm 0.4$ & $40.3 \pm 2.4$ & $0.43 \pm 0.06$ & $15.2 \pm 0.41$
\end{tabular}

${ }^{a}$ Mixing on the basis of wet weight.

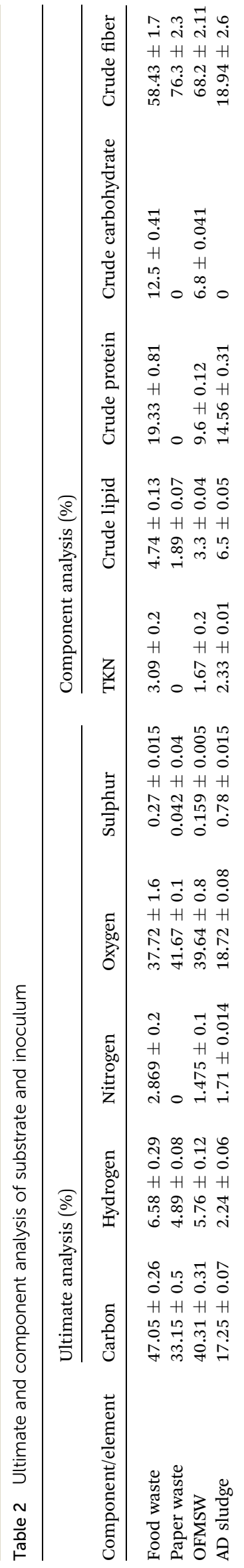


a)

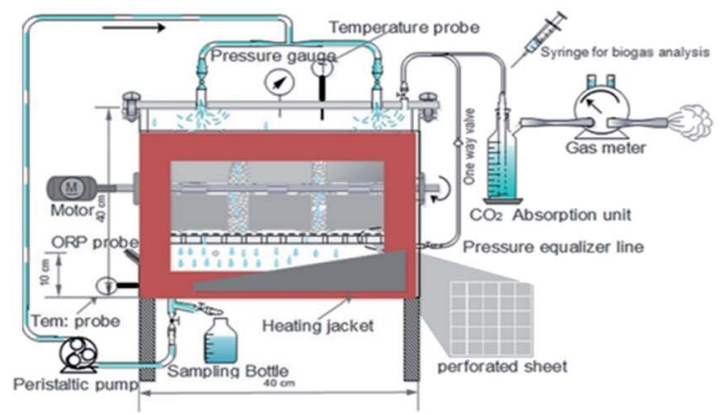

(b)

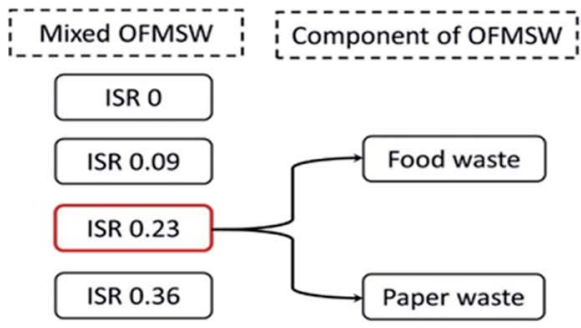

Fig. 1 (a) Schematic representation of percolator reactor and (b) experimental setup.

The reactor was manufactured by BAXH environment system Co. Ltd. Beijing. The reactor was designed, in accordance with the literature, with a surface to volume ratio of 2.5 , to avoid sideeffects at the reactor walls. ${ }^{33}$ The height of reactor was divided into top and bottom sections and were separated by a perforated sheet (diameter $0.5 \mathrm{~mm}$ and $15 \%$ perforation area) positioned $10 \mathrm{~cm}$ from the bottom of the reactor. While this arrangement facilitates to hold the solid substrate, a geotextile sheet was placed on the perforated sheet to avoid migration of solid particles into a bottom section of the reactor, thus creating a $5 \mathrm{~L}$ volume at the lower part of the reactor for temporary leachate collection and storage. The leachate was recirculated with the help of a peristaltic pump (WT600-2J) to the upper part of the reactor and is uniformly distributed at the surface by means of a sprinkler. Backwashing, to clear the blockages in the perforated sheet, was done by using a peristaltic pump (in reverse direction).

Two sets of laboratory-scale experiments were performed to determine separation of biodegradable organic carbon from OFMSW at liquid to solid ratio (L/S) 5( $\left.48 \mathrm{~g} \mathrm{VS} \mathrm{L}^{-1}\right)$. Experimental setup is as shown in Fig. $1 \mathrm{~b}$. In the first set of experiments, three different ISR were used $(0.09,0.23$ and 0.36$)$ and compare with control (ISR 0) to determine the effect of ISR on hydrolysis and acidification for the optimization of process. In the second set of experiments, the acidogenic fermentation for sole components of OFMSW (PW and FW) at optimized ISR 0.23 to explore the synergistic effect.

All the experiments were done in duplicate, while the optimized batch was run in triplicate to ensure the authenticity of the results. The percolation reactor was operated with a hydraulic retention time (HRT) of $120 \mathrm{~h}$ at mesophilic temperature $35 \pm 2$.

\subsection{Analytical methods}

The concentrations of total solids (TS), volatile solids (VS), chemical oxygen demand (COD), nitrogen-ammonium $\left(\mathrm{NH}_{4}{ }^{+}\right.$ $\mathrm{N}), \mathrm{pH}$, total kjeldahl nitrogen (TKN) were identified according to Standard Methods. ${ }^{34}$ Crude protein and lipids concentration were determined by TKN (multiplied by a factor of 6.25) and Soxhlet extraction method with petroleum ether used as organic solvent respectively. Biodegradability batch analyses was performed in accordance with the guidelines defined by
Angelidaki. ${ }^{35}$ The elemental analysis (CHNOS) was performed with an elemental analyzer (Equipment CE 440; EAI USA). Dissolved organic carbon (DOC) was measured by using TOC analyzer (TOC-Vcph), Shimadzu, Kyoto, Japan.

Volatile fatty acid (VFA) were measured using a gas chromatograph (GC-2014; Shimadzu, Japan) equipped with a capillary column (Stabilwax-DA, $30 \mathrm{~m} \times 0.32 \mathrm{~mm} \times 0.25 \mu \mathrm{m}$; Restek, Bellefonte, PA, USA) and flame ionization detector. A detailed description of the methodology to analyze VFAs is described in the literature elsewhere. ${ }^{32}$ The concentration of proteins and reducing sugars were measured by using Lowry-Folin with bovine serum albumin (BSA) as standard, ${ }^{36}$ Dinitrosalicylic acid method with glucose as a standard, ${ }^{37}$ respectively. The samples were centrifuged for 10 minutes at $10000 \mathrm{rpm}$ and then were filtered $(0.45 \mu \mathrm{m})$. To determine soluble COD, DOC, VFA, TAN, reducing sugar and protein, the same method as discussed above was adopted. The VFAs yield was calculated as the sum of the measured acetic, $n$-butyric, propionic, iso-valeric, $n$-valeric and iso-butyric acids. The conversion factors used for determination of the chemical oxygen demand (COD) of soluble organic materials were 1.07 for $\mathrm{g} \mathrm{COD} \mathrm{g}^{-1}$ acetic acid, 1.5 for $\mathrm{g}$ $\mathrm{COD} \mathrm{g}^{-1}$ protein (assumed as $\left.\left(\mathrm{C}_{4} \mathrm{H}_{6.1} \mathrm{O}_{1.2} \mathrm{~N}\right)_{x}\right), 2.04$ for $\mathrm{g}$ COD $\mathrm{g}^{-1}$ valeric acid, 1.51 for $\mathrm{g}$ COD $\mathrm{g}^{-1}$ propionic acid, 1.82 for $\mathrm{g}$ COD g ${ }^{-1}$ butyric acid and $1.07 \mathrm{~g}^{-} \mathrm{COD} \mathrm{g}^{-1}$ reducing sugar $\left(\mathrm{C}_{6} \mathrm{H}_{12} \mathrm{O}_{6}\right)$.

\subsection{Analytical techniques}

2.4.1 Hydrolysis efficiency. The hydrolysis efficiency $\left(\eta_{\mathrm{Hy}}\right)$ is defined as the ratio of SCOD in the leachate to the initial dry chemical oxygen demand (TCOD) of the biodegradable substrate, is calculated by eqn (1).

$$
\eta_{\text {hydrolysis (sCOD) }}=\frac{\mathrm{sCOD}_{t=i}}{\operatorname{TCOD}_{t=0}} \times 100
$$

2.4.2 Acidification efficiency. The acidification efficiency $\left(\eta_{\mathrm{Ac}}\right)$ is defined as the ratio of the cumulative total VFA (COD) and soluble COD in the leachate and is calculated from eqn (2)

$$
\eta_{\text {acidification (sCOD) }}=\frac{\mathrm{VFA}_{\mathrm{sCOD}, t=i}}{\mathrm{sCOD}_{t=i}} \times 100
$$

where TCOD is the initial total COD $(\mathrm{g})$ concentration of the substrate; SCOD is the cumulative soluble COD concentration 
(g) with a particular time in the leachate, and VFA is the cumulative total VFA concentration ( $\mathrm{g}$ COD) in the leachate.

2.4.3 Kinetics. Solubilization or liquidation of OFMSW is generally considered as two-step processes, hydrolysis, and acidogenesis; it can be expressed in eqn (3)

$$
\mathrm{OFMSW}_{\mathrm{VS}} \stackrel{\text { hydrolysis }}{\longrightarrow} \text { monomers } \mathrm{SCOD} \stackrel{\text { acidfication }}{\longrightarrow} \text { acids }_{\mathrm{VFA}}
$$

where OFMSW is a polymeric biodegradable substance of carbohydrate, protein, and fat (i.e., volatile solids), it gradually hydrolyzed into soluble monomers (i.e., sCOD) that can be further converted by acidogenesis into the fatty acids, i.e., VFA $\left(\mathrm{C}_{2}-\mathrm{C}_{6}\right)$. The hydrolysis step can be described by the first-order reaction kinetics, which has been considered as the most appropriate for complex heterogeneous substrates. ${ }^{19,38,39}$ According to Vavilin et al. ${ }^{39}$

The relationship between substrate and product under the first order kinetics, it expressed in eqn (4) and (5).

$$
\begin{gathered}
\frac{\mathrm{dVS}}{\mathrm{d} t}=-k \mathrm{VS} \\
\frac{\mathrm{dsCOD}}{\mathrm{d} t}=\alpha k \mathrm{VS}
\end{gathered}
$$

where VS is the volatile solids (VS) concentration, SCOD is the product concentration, $k$ is the first-order rate constant, and $\alpha$ is the conversion coefficient of substrate to product. After integration of eqn (4) and (5), the product concentration is expressed as

$$
\mathrm{sCOD}=\mathrm{sCOD}_{i=0}+\alpha \mathrm{VS}_{i=0}\left(1-\mathrm{e}^{-k_{\mathrm{h}} t_{i}}\right)
$$

where $\mathrm{sCOD}_{0}$ and $\mathrm{VS}_{0}$ are the initial product and substrate concentrations, respectively. A non-linear regression would be used to estimate the values of hydrolysis rate reaction (per hour) and coefficient $\alpha$ and their standard deviations. The logistic model is widely used for acidogenesis kinetics, which is related to the bacterial activity ${ }^{\mathbf{3 8 , 4 0 , 4 1}}$ as shown in eqn (7)

$$
\mathrm{VFA}_{t=i}=\frac{\mathrm{VFA}_{\text {mix }}}{1+\left(\frac{\mathrm{VFA}_{\text {mix }}}{\mathrm{VFA}_{t=0}}\right) \mathrm{e}^{-K_{\mathrm{VFA}} t_{i}}}
$$

where VFA, $\mathrm{VFA}_{\text {mix }}$, and $K_{\mathrm{VFA}}$, are the VFAs concentration at time $t$ and the maximum VFAs concentration, apparent specific rate constant $\mathrm{h}^{-1}$ respectively.

\section{Results and discussion}

\subsection{Effect of ISR on process performance of acid fermentation}

3.1.1 Bulk characterizations of leachate parameters: $\mathbf{p H}$, soluble organics, $\mathbf{N H}_{4}{ }^{+}-\mathbf{N}$ and alkalinity. The evolution of the main leachate parameters, such as $\mathrm{pH}$, ammonia, alkalinity and soluble organic components, happened during the acid fermentation at different ISR (namely 0, 0.09, 0.23 and 0.36, respectively), are shown in Fig. 2.

The stable performance of acid fermentation is influenced mainly by the accumulation of organic acids and decrease of $\mathrm{pH}$. The positive effects of ISR addition on $\mathrm{pH}$ increase at the initial stage of fermentation were observed. In particular, an initial $\mathrm{pH}$ value of $6.4-7.2$, when using ISR $>0.09$. As the fermentation proceeded, the $\mathrm{pH}$ values of reactors with ISR 0.23 and 0.36 decreased slowly and maintained a relatively stable level of 5.5 throughout the experimental period. However, $\mathrm{pH}$ values in ISR 0.09 and control reactors were dropped to $\sim 4.0$ 4.5 , which is below the optimal value for acid fermentation. ${ }^{12}$

The results regarding ammonia concentration are pointed out in Fig. 2a. Ammonia concentrations in ISR 0.23 and 0.36 reactors showed an increasing trend with time and reached to $\sim 1100 \mathrm{mg} \mathrm{L}^{-1}$ by the end of the experiment. In contrast, the
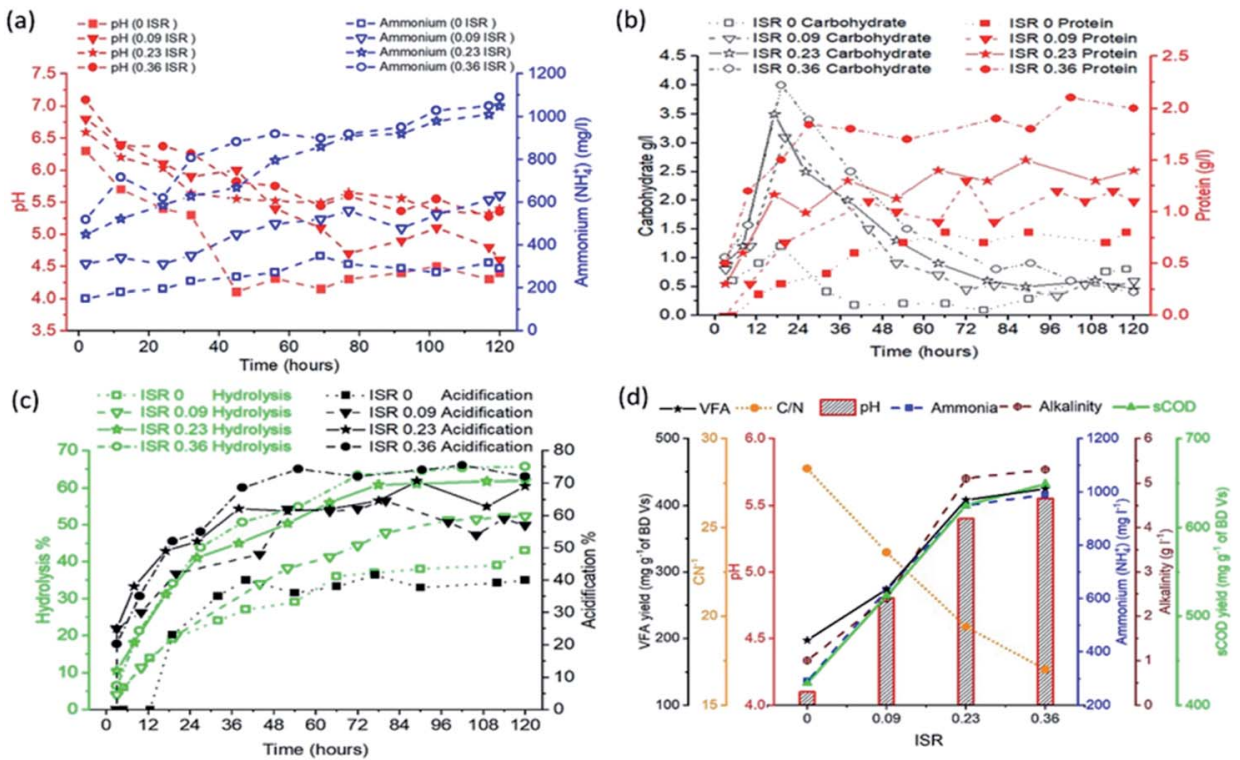

Fig. 2 Results of acid fermentation of OFMSW at different ISR (0-0.36) values (a) pH and ammonia, (b) soluble carbohydrate and protein released (c) hydrolysis and acidification efficiency (d) summary of overall results at the end of experiments. 
initial $\mathrm{NH}_{4}{ }^{+}-\mathrm{N}$ concentrations in ISR 0 and 0.09 reactors were obviously lower, and increased slightly in the subsequent days of acid fermentation, with the final values of 300 and $600 \mathrm{mg} \mathrm{L}^{-1}$, respectively (Fig. 2d). These discrepancies of ammonia concentration among each reactor can be attributed to the higher protein content due to higher ISR (e.g., more inoculum addition) (Table 2). Furthermore, the obtained ammonia could provide alkalinity (Fig. 2d) and neutralize VFAs produced in acid fermentation, ${ }^{20}$ thus resulting in higher $\mathrm{pH}$ values in the fermentation liquor $(\sim 5.5)$.

The soluble carbohydrate concentrations in all the reactors decreased rapidly after the initial peak at hours 18-24 (Fig. 2b).

However, it was observed that the maximum concentration of soluble carbohydrate was $4000 \mathrm{mg} \mathrm{L}^{-1}$ at ISR 0.36 which was almost 4-folds higher than that without inoculum. This result can be explained by accelerated hydrolysis achieved due to the application of high ISR. In contrast, the concentration of soluble protein increased gradually in all the reactors, implying the biological transformation of protein usually occurs after carbohydrate degradation and requires extended period. ${ }^{\mathbf{4 2}}$

3.1.2 VFAs profiles. The evaluation of VFA composition is important as it provides useful information regarding the metabolic pathway and helps to understand its end-user application. The evolution of VFAs production at different ISR during the whole experimental period is given in Fig. 3.

With the progress in hydrolysis and acidification process, the concentrations of VFAs increased steadily in all reactors, ranging from 16 to $24 \mathrm{~g} \mathrm{COD} \mathrm{L}^{-1}$ by the end of the study. It should be noted that the increase in ISR enhanced the VFAs production. At ISR 0, it was observed that the VFAs production was $\sim 197 \mathrm{mg} \mathrm{g}^{-1}$ VS, which was the lowest yield in all ISR reactors.

The VFAs production from ISR 0.23 and 0.36 reactors reached 377 and $410 \mathrm{mg} \mathrm{g}^{-1} \mathrm{VS}$, respectively, which are $\sim 1.9$ and $\sim 2.1$ times higher compared with the control.

During the later phase of test, the concentrations of VFAs from ISR 0.23 and 0.36 reactors still maintained at relative and high level, possibly as the accumulation of fatty acids alters the system buffering condition leading to retardation of the rate of VFA production.

Butyric was dominating in all batches during the initial stage. Subsequently, butyrate-type fermentation was observed corresponding to the low ISR (e.g. 0 and 0.09), possibly due to $\mathrm{pH}$ effort. In contrast, it was observed that when ISR $\geq 0.23$, butyrate type fermentation shifted to mixed-type and acetic-type fermentation which includes $42-53 \%$ of acidic acids and $\sim 14 \%$ of propionic. Hawkes et $a l .{ }^{43}$ reported that, with the increase in
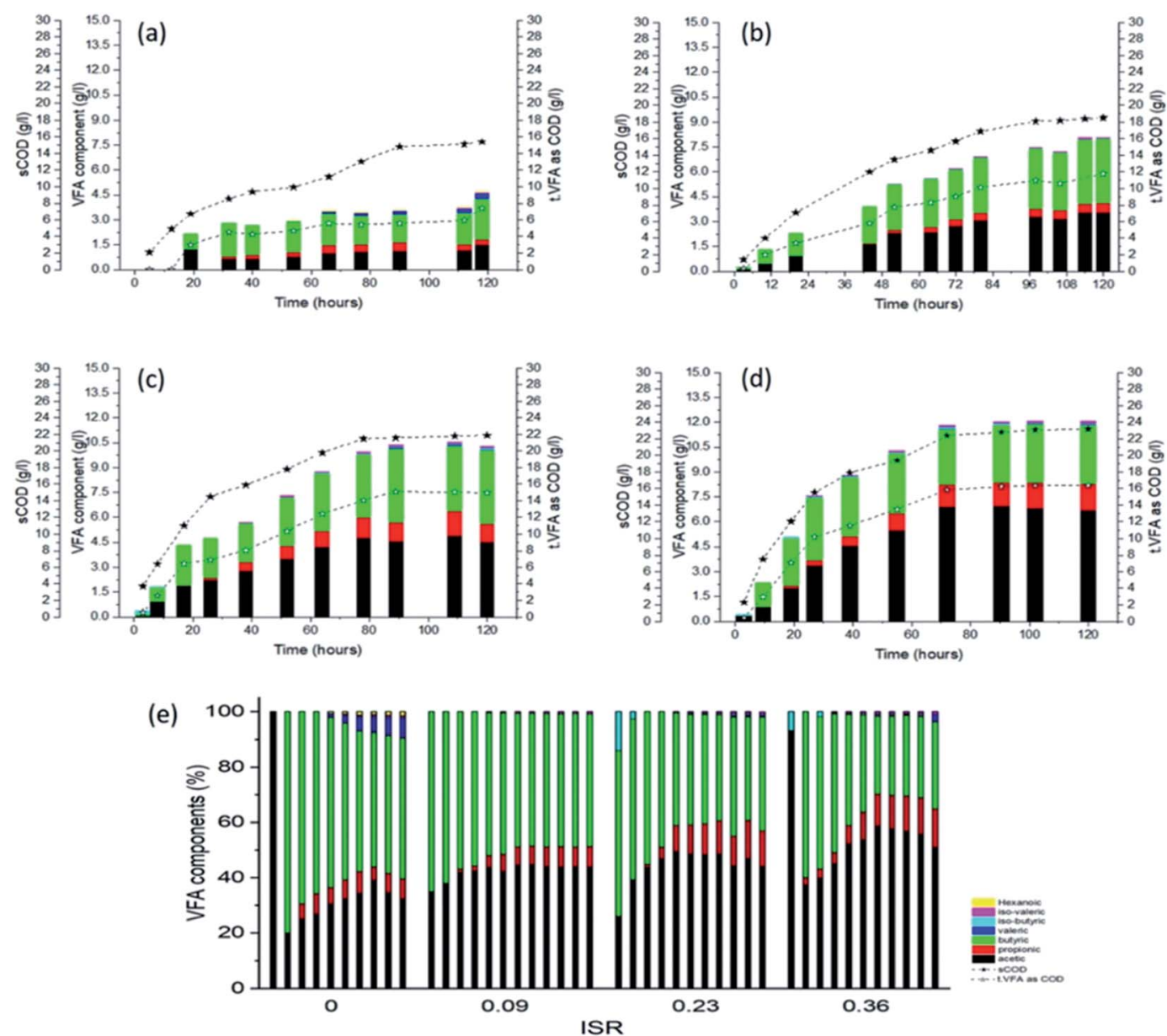

Fig. 3 sCOD and VFA concentration and VFA composition under different ISR from OFMSW. (a) ISR 0, (b) ISR 0.09 (c) ISR 0.23 (d) ISR 0.36 and (e) overall compression of VFA compositions. 
the $\mathrm{pH}$, butyric was converted to acidic and propionic acid and the authors attributed the change could be because of change in the dominant microbial species or change in the metabolic pathway within the same bacterial population. In the present study, the propionic acid accumulation was noticed at relatively low levels in ISR 0.23 and 0.36 reactors, which was suitable for the subsequent usage, such as methane production.

The comprehensive comparison of VFAs production in this study with the studies reported in literature is showed in Table 4. The positive effects of optimizing ISR addition, without $\mathrm{pH}$ adjustment, on acids production were satisfactory.

3.1.3 Hydrolysis and acidification extent. The hydrolysis and acidification efficiencies were calculated using eqn (1) and (2), respectively, and are shown in Fig. 2c. Additionally, the kinetic parameters were also analysed according to the eqn (3), by applying first-order kinetics eqn (6) and logistic model eqn (7), and the result are depicted in Table 3 and Fig. 4.

The increase in ISR had a direct influence on the hydrolysis and acidification efficiencies: the highest hydrolysis and acidification efficiencies were $64 \%$ and $74 \%$, respectively, at ISR 0.36 , followed by ISR $0.23\left(\eta_{\mathrm{Hy}}: 62\right.$ and $\left.\eta_{\mathrm{Ac}}: 70\right)$, ISR $0.09\left(\eta_{\mathrm{Hy}}: 50\right.$ and $\left.\eta_{\text {Ac }}: 60\right)$ and control ISR 0 ( $\eta_{\mathrm{Hy}}: 40$ and $\left.\eta_{\text {Ac }}: 40\right)$. Overall, hydrolysis rate as stipulated by the increasing production in SCOD from 0.019 to 0.038 per hour was observed as ISR was increased from 0 to 0.36 . ISR 0.036 had a maximum value for $\alpha, K_{\mathrm{h}}$ and VFA $_{\text {max }}$, which were $0.456,0.0381 \mathrm{~h}^{-1}$ and $15.9 \mathrm{~g} \mathrm{~L}^{-1}$, receptively. These values were almost two-fold higher than the control (ISR 0). The hydrolysis rate constant (0.91 per day) obtained at the ISR 0.36 in this study was much higher than the reported value, ${ }^{44}$ which was due to high OLR used in this study.

However, it is worth to note that a slightly decrease of $K_{\mathrm{VFA}}$ appeared with ISR 0.36 as compared to ISR 0.23 , which might be attributed to quicker VFAs degradation with more inoculum addition. Similar result was also reported by Tomei et al. ${ }^{\mathbf{4 5}}$ Hence, ISR 0.23 was chosen as optimal parameter in order to avoid the undesired loss of organic carbon in substrate.

\subsection{Comparison of individual component and OFMSW for the process performance}

The pH of components of OFMSW (PW and FW) and mixed OFMSW were not adjusted artificially during fermentation process; they fluctuated in a range of 7.2-7.5, 4.1-6.5 and 5.46.5 , respectively. Sole PW and FW fermented at ISR 0.23 and 120 HRT is shown in Fig. 5.

The soluble products during the acidogenic fermentation of sole $\mathrm{PW}$ was observed to be lowest and, in contrast, the $\mathrm{pH}$ was observed to be highest as compared to FW and OFMSW. Due to the high $\mathrm{C} / \mathrm{N}$ ratio, around 96 , which imply that sufficient nitrogen is not available for the synthesis of bacteria to degrade the cellulosic natured substrate. This could be the possible reason for not recommending sole PW for acidification. ${ }^{30}$

Sole FW hydrolysis was noticed to rapidly increase up to $66 \%$ with highest production of SCOD $28 \mathrm{~g} \mathrm{~L}^{-1}$. On the other hand, $\mathrm{pH}$ rapidly dropped to reach the lowest value, 4.2 , during the first $60 \mathrm{~h}$. Acidification efficiency started from 40\%, which was highest.

Table 3 Kinetic parameter for the hydrolysis and acidification steps during OFMSW fermentation at different ISR

\begin{tabular}{llllll}
\hline Stage & Parameters & ISR 0 & ISR 0.09 & ISR 0.23 & ISR 0.36 \\
\hline Hydrolysis & $\alpha$ & $0.307 \pm 0.012$ & $0.371 \pm 0.023$ & $0.4345 \pm 0.041$ & $0.456 \pm 0.047$ \\
& $K_{\mathrm{h}}\left(\mathrm{h}^{-1}\right)$ & $0.019 \pm 0.005$ & $0.022 \pm 0.0063$ & $0.0366 \pm 0.0071$ & $0.0381 \pm 0.0052$ \\
& $R^{2}$ & 0.976 & 0.998 & 0.992 & 0.997 \\
Acidogenesis & $\mathrm{SE}$ & 0.003 & 0.0012 & $13.53 \pm 0.340$ \\
& $\mathrm{VFA}_{\max }\left(\mathrm{g} \mathrm{L}^{-1}\right)$ & $7.395 \pm 0.347$ & $11.722 \pm 0.417$ & $0.0803 \pm 0.0099$ & 0.006 \\
& $K_{\text {VVA }}\left(\mathrm{h}^{-1}\right)$ & $0.0465 \pm 0.0049$ & $0.0494 \pm 0.0057$ & 0.979 & $0.0790 \pm 0.0113$ \\
& $R^{2}$ & 0.965 & 0.978 & 0.008 & 0.0009
\end{tabular}
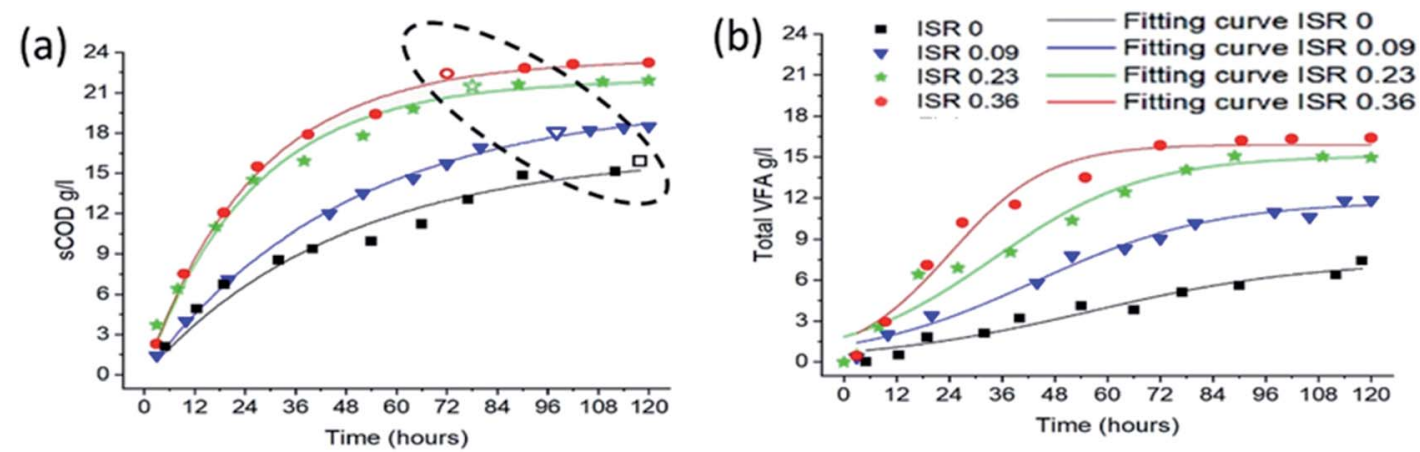

Fig. 4 Kinetic analysis of different ISR during the hydrolysis and acidification process. (a) SCOD production under different ISR. (b) T VFA production under different ISR. 
(a)

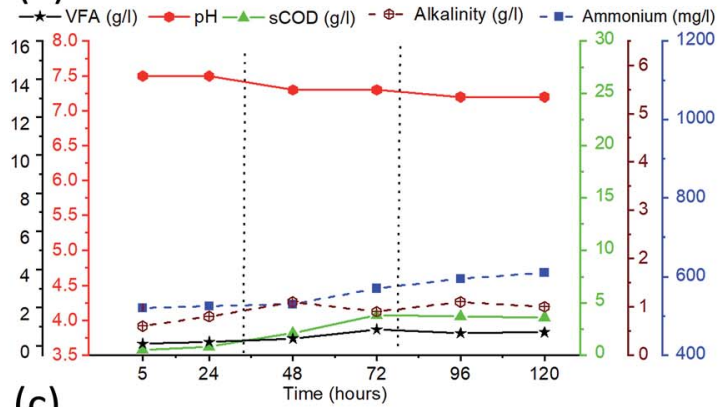

(c)

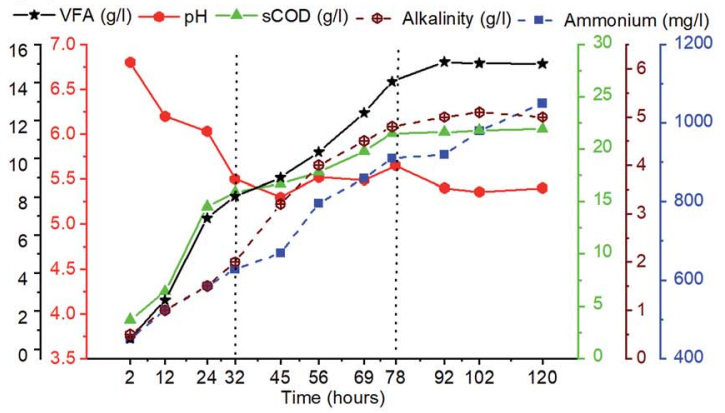

(b)

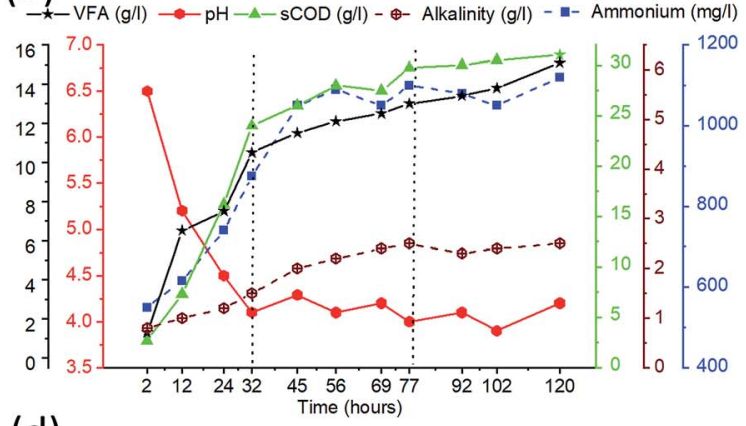

(d)

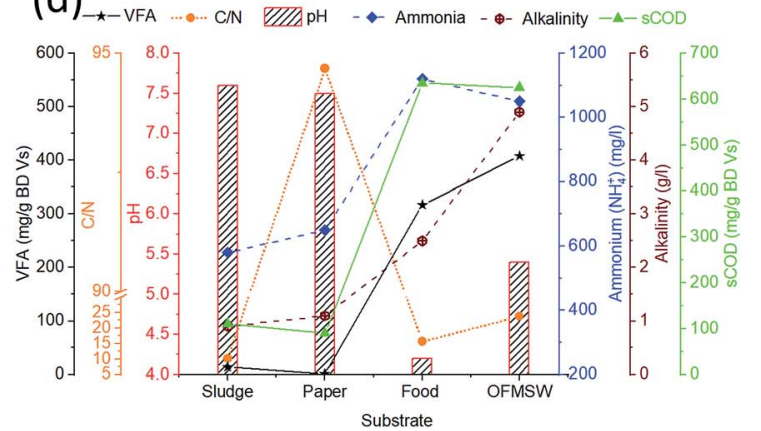

(e)

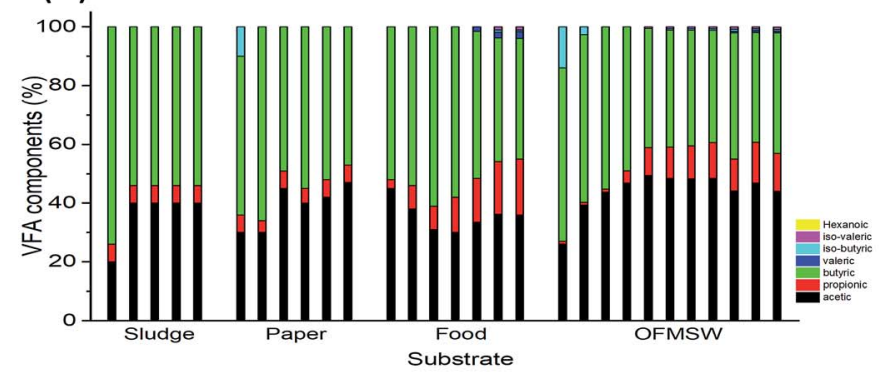

Fig. 5 sCOD and VFA production of mono and mixed fermentation at ISR 0.23. (a) Mono fermentation of PW (b) mono fermentation of FW (c) mixed fermentation of OFMSW (d) summary of overall result and (e) overall compression of VFA composition from mono to mixed fermentation.

However, acidification efficiency was almost same throughout the experiments while the efficiency of OFMSW increased up to $70 \%$ at the end of experiments. It was noticed that the accumulation of carbohydrate and protein was 2 and $2.5 \mathrm{~g} \mathrm{~L}^{-1}$, respectively, which is $c a$. two-fold higher than the OFMSW. These results indicated that process of acidification and hydrolysis was suppressed due to the low $\mathrm{pH} 4.2$, the organic acids freely pass through the cell membrane of microbes, consequently inhibited the overall acidogenic process. ${ }^{47}$ Similar results were reported by Jiang et $a l .{ }^{5}$ and $\mathrm{Wu}$ et al. ${ }^{6,21}$

Acidogenic fermentation of mixed OFMSW (FW and PW at mixing ratio of $55: 45$ by $\mathrm{VS}$ ), during the initial phase of hydrolysis, soluble part of carbohydrate and protein from FW rapidly converted into VFA which caused a sudden drop in $\mathrm{pH}$ to 5.4 within 32 hours, which is $26 \%$ higher than sole FW. Consequently, the hydrolysis efficiency and acidification efficiency reached to $45 \%$ and $40 \%$, respectively. Ammonia concentration showed contrasting values, i.e., $1050 \mathrm{mg} \mathrm{L}^{-1}$,
8.6\% lower than FW and plausible reason could be the higher protein content in FW as compared to OFMSW as shown in Fig. 5 and Table 2. It can be concluded that ammonia is not the only parameter responsible for the $\mathrm{pH}$ stabilization in mixed fermentation.

After initial phase, PW would be hydrolyzed due to favorable pH conditions. ${ }^{48}$ Hydrolysis of PW provides two opportunities, (1) cellulose degrade into glucose, which is the most suitable substrates for VFA production. (2) It releases carbonates, a major additive in PW which accounts $c a$. 21\%. Ultimately, in this case, alkalinity increased from 2 to $5 \mathrm{~g} \mathrm{~L}^{-1}$ which is two-fold higher than sole FW. In this way performance of mixed fermentation process was much better than the sole FW, especially after the initial phase $\mathrm{e}^{\mathbf{3 1 4 9}}$ shown in Fig. $5 \mathrm{a}$, the $\mathrm{pH}$ of mixed fermentation was in the range of 5.3-5.5, is optimal for hydrolysis as well as acidification. ${ }^{\mathbf{2 1}}$ The hydrolysis and acidification efficiency, and ammonia gradually increased from 40$64 \%, 50-70 \%$, and $600-1050 \mathrm{mg} \mathrm{L}^{-1}$ respectively. The soluble carbohydrate and protein were stable due to their balanced 
conversion to VAF. During the course of time the overall $\mathrm{pH}$ was stable. The results demonstrated that fermentation of OFMSW concurrently accelerated the substrate acidification. It affects the composition of VFA and butyric acid was reduced from 60$40 \%$ in contrast to the acetic acid which increased from 26$41 \%$, due to the $\mathrm{pH}$ uplift from 4.2 to 5.4 (sole FW to mixed OFMSW) recorded among all batches investigated in the present study and it might be due to plenty of soluble carbohydrate available in fermentation broth. ${ }^{21}$

3.2.1 Synergistic effect. The synergistic effect is the internal reaction produced by the fermentation of different types of substrate. ${ }^{50}$ In current study, two individual components from OFMSW (paper, and food) compared with mixed OFMSW were selected. Moreover, it can be mathematically expressed in eqn (8).

$$
\alpha=\text { Experimental Yield/Theoretical Yield }
$$

where "Experimental Yield" represented as a hydrolysis and acidification yield obtained from fermentation of OFMSW. "Theoretical Yield" was calculated as the sum of soluble products, each substrate multiplied by its percentage in the mixture of biodegradable portion of VS. "Theoretical Yield" can be calculated as eqn (9). ${ }^{51}$

$$
\text { Theoretical yield }=\text { yield }_{\text {Paper }} \times \text { paper }_{\% \mathrm{BD}}+\text { yield }_{\text {Food }} \times \text { food }_{\%}
$$
$\mathrm{BD}$

where, yield Paper $_{\text {and yield }}$ Food are the experimental sCOD and VFA yields of mono-fermentation of PW and FW respectively. Paper $_{\% \mathrm{BD}}$ and food $_{\% \mathrm{BD}}$ are referred to the mixing ratio from fermentation mixture. Synergistic effect evaluation was based on the biodegradables, COD and carbon. Summarized synergistic analysis for mixed fermentation of PW and FW is presented in Table 5. Zero effect consider being for inoculum on sole and mixed in acidogenic fermentation. Because sludge has low biodegradation around $15 \%$ and its biodegradable part contributing to VFA and soluble carbohydrate is less than $10 \%$, it showed very negligible effect.

Overall maximum synergistic effect was found on acidification (VFA) with $76 \%$ and $59 \%$ of carbon and COD, respectively. It also affected hydrolysis in $35 \%$ and $24.6 \%$ of carbon and COD respectively. A slight synergistic effect has been observed in biodegradability. There are two plausible possible reasons for synergies enhancing during hydrolysis and acidification; the first reason could be due to achieved $\mathrm{pH}(5.2-5.6)$ which is favorable for acidogenic fermentation (detail discuss in $\mathrm{pH}$ section). ${ }^{12}$ Same results were observed during the cofermentation of food and excess sludge. ${ }^{21}$ At this $\mathrm{pH}, \mathrm{PW}$ hydrolyzes into soluble carbohydrate; it was the preferred substrate by the microbes. It is firstly degraded to glucose, then to pyruvate. Pyruvate is an important intermediate product that is readily oxidized to acetyl-CoA, which can be further utilized to produce acetic and butyric by diverse enzymatic actions. ${ }^{52}$ Elliston et $a l .{ }^{53}$ reported that the PW would be hydrolyzed under pH 5-5.5. The second reason might be microbial shift change due to the mixed fermentation, although no significant evidence was observed in the present study. It was suggested that bacteria, such as Clostridium the ocellus, may facilitate the extraction of cellulose from waste paper, which facilitates the degradation of cellulosic materials. ${ }^{54}$ Further research is required to determine the presence of cellulose-secreting microorganisms within the culture.

\subsection{Carbon balance analysis}

The carbon mass balance explains the electron flow through the anaerobic process ${ }^{12}$ and optimized conditions (ISR 0.23 , results discussed in Section 3.2) were applied for PW, FW and OFMSW and shown in Fig. 6. In general, carbon represents the organic carbon from organic waste in the form of biodegradable portion of VS. It is reported that the organic carbon can be converted

\begin{tabular}{|c|c|c|c|c|c|c|c|}
\hline \multirow[b]{2}{*}{ Substrate } & \multirow[b]{2}{*}{ Seeding } & Optimal condition & \multirow[b]{2}{*}{$\begin{array}{l}\text { Reactor mode } \\
\text { and capacity }\end{array}$} & \multirow[b]{2}{*}{ Ac: \% \& Hy: \% } & \multirow[b]{2}{*}{ VFA production } & \multirow[b]{2}{*}{$\mathrm{pH}$} & \multirow[b]{2}{*}{ Ref. } \\
\hline & & $\begin{array}{l}\mathrm{Temp}^{*}{ }^{\circ} \mathrm{C}, \mathrm{OLR}^{+} \mathrm{g} \text { VS } \mathrm{L}^{-1}, \\
\mathrm{ISR}^{\wedge}, \mathrm{SRT}^{\mathrm{x}} \text { days \& particle } \\
\mathrm{size}^{\dagger} \mathrm{mm}\end{array}$ & & & & & \\
\hline FW : ES & WAS & $40^{*}, 9^{+}, 0.2^{\wedge}, 7^{\mathrm{x}} \& \mathrm{ND}^{\dagger}$ & Semi-conti. & Ac: $83 \%$ \& Hy: $63 \%$ & $867 \mathrm{mg} \mathrm{g}^{-1} \mathrm{VS}$ & 5.2 not fixed & 21 \\
\hline FW & AD sludge & $35^{*}, 11^{+}, 8^{\mathrm{x}} \& \mathrm{ND}^{\dagger}$ & Batch, $4.5 \mathrm{~L}$ & Ac: $75 \%$ & $\begin{array}{l}471 \mathrm{mg} \mathrm{g}^{-1} \mathrm{VS} \\
\text { removal }\end{array}$ & 6 adj & 6 \\
\hline OFMSW $^{\mathrm{a}}$ & AD sludge & $55^{*}, 44.4^{+}, 1.9^{\mathrm{x}} \& 15 \mathrm{~mm}$ & Semi-conti., $10 \mathrm{~L}$ & Ac: $61 \%$ \& Hy: $59.6 \%$ & ND & 5-5.5 adj & 46 \\
\hline FW & AD sludge & $35^{*}, 9^{+}, 8^{\mathrm{x}} \& \mathrm{ND}^{\dagger}$ & Semi-conti., $2 \mathrm{~L}$ & Ac: $63 \%$ & $\begin{array}{l}333 \mathrm{mg} \text { COD } \\
\text { per g VS }\end{array}$ & $5.5 \mathrm{adj}$ & 28 \\
\hline OFMSW $^{\mathrm{b}}$ & A.S.C & $35^{*}, 28^{+}, 80^{\mathrm{x}} \& 4^{\dagger}$ & LBR, $5 \mathrm{~L}$ & Ac: $60 \%$ \& Hy: $61 \%$ & $7 \mathrm{~g} \mathrm{~L}^{-1}$ & $5.5 \mathrm{adj}$ & 26 \\
\hline OFMSW & AD sludge & $\begin{array}{l}37^{*}, 48^{+}, 0.23^{\wedge} 3.25^{\mathrm{x}} \& \\
40-50 \mathrm{~mm}\end{array}$ & Percolator B, $20 \mathrm{~L}$ & Ac: $65 \%$ \& Hy: $64 \%$ & $\begin{array}{l}377.5 \mathrm{mg} \text { sCOD } \\
\text { per g VS }\end{array}$ & 5.5 not fixed & $\begin{array}{l}\text { Current } \\
\text { study }\end{array}$ \\
\hline
\end{tabular}

Table 4 Comparison of VFAs production from different modes of fermentation and at different operational conditions in literature ${ }^{a}$

${ }^{a}$ A.S.C $=$ acidogenic seed culture. $\mathrm{ND}=$ not define (crushed by an electrical blender) ${ }^{\dagger}, \mathrm{FW}=$ food waste, $\mathrm{KW}=\mathrm{kitchen}$ waste, $\mathrm{ES}=$ excess sludge, $\mathrm{AD}=$ anaerobic digestion. WAS $=$ waste activated sludge, $\mathrm{PW}=$ paper waste, $\mathrm{Ac}=$ acidification, $\mathrm{C} . \mathrm{Ac}=$ carbon acidification, $\mathrm{Hy}=$ hydrolysis, $\mathrm{SRT}=$ solid retention time $\mathrm{Adj}=$ adjustable. OFMSW ${ }^{\mathrm{a}}$ derived from MBT and component doesn't show. OFMSW ${ }^{\mathrm{b}}$ derived from mixture of fruit, vegetable and kitchen waste. 
Table 5 Synergistic effects of hydrolysis and acidification during fermentation of OFMSW

\begin{tabular}{lllcccc}
\hline Parameters & & Paper & Food & OFMSW (theoretical) & OFMSW (experimental) & Synergistic effect \\
\hline \multirow{2}{*}{ COD } & Biodegradability & 0.6 & 0.7 & 0.655 & 0.7 & 1.069 \\
& SCOD $\left(\mathrm{g}^{-1} \mathrm{~L}\right)$ & 3.5 & 28.5 & 17.25 & 21.5 & 1.246 \\
\multirow{3}{*}{ Carbon } & VFA $\left(\mathrm{g}^{-1} \mathrm{~L}\right)$ & 0.805 & 15.105 & 8.813 & 14.1 & 1.59 \\
& Biodegradability & 0.55 & 0.65 & 0.605 & 0.65 & 1.074 \\
& DOC $\left(\mathrm{g}^{-1} \mathrm{~L}\right)$ & 1.56 & 9.8 & 6.092 & 8.2 & 1.35
\end{tabular}

into a wide range of products during hydrolysis-acidification process of anaerobic digestion.

Mainly it can be converted into three forms, (1) soluble liquid fraction, into VFAs, proteins, carbohydrate, lactic acid, and alcohols. ${ }^{6}$ (2) Gaseous fraction, carbon dioxide and methane, ${ }^{12}$ (3) solid fraction (solid residue).

The gaseous and solid fraction were measured at the start and end of the experiment, while the soluble liquid fraction was measured during the experiment. Gaseous fraction and suspended part of the liquid fraction was mathematically calculated by subtracting the soluble liquid and final solid residue from the initial carbon that is represented as "uncountable carbon." The quantity of carbon in a soluble liquid fraction was quantified in terms of DOC. Furthermore, carbon distribution in a soluble protein, carbohydrate and VFA were measured according to the molecular weight of the chemical formula. ${ }^{15}$

Sole sludge effect was negligible because sludge has a low biodegradability around $15 \%$ as shown in Table 5. A major portion of carbon in sludge was accountable for solid residue and uncountable part of carbon. The carbon represented by solid residue and VFA were dominant in paper, food and OFMSW, respectively. Additionally, the solid residue mass in $\mathrm{PW}$, protein, carbohydrate and uncountable mass in $\mathrm{FW}$ also showed greater percentages than in OFMSW and were $80 \%$, $12 \%, 6 \%$ and $10 \%$ of the total carbon, respectively.

This data indicated that the fermentation substrates in PW and FW were not adequately utilized to produce VFAs. However, the carbon masses of protein, carbohydrate and uncountable carbon in FW are much higher than OFMSW, these parts of carbon might be converted into VFA and another soluble part of the carbon into OFMSW.

Biodegradable carbon represented by VFA in FW and OFMSW were $30 \%$ and $42 \%$, respectively. Mixed fermentation

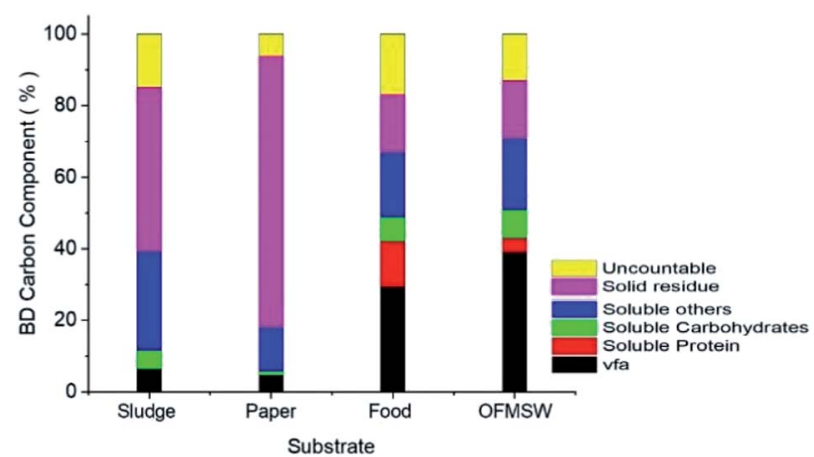

Fig. 6 Percentage of different component of biodegradable carbon of mono and mixed fermentation, at HRT $120 \mathrm{~h}$. has more than $70 \%$ of biodegradable solid carbon converted into liquid carbon, which is more than the sole component of OFMSW (FW and PW).

\section{Conclusions}

A novel, practical and cost-effective strategy for the converting biodegradable carbon of OFMSW into VFA via acidogenic fermentation without $\mathrm{pH}$ control has been proposed. The optimized VFA production by fermentation of OFMSW (FW + $\mathrm{PW}$ ) at ISR 0.23 adjustment was attributed to favorable $\mathrm{pH}, 5.5-$ 5.2 , achieved, which subsequently enhanced the hydrolysis and acidification. The maximum synergies were observed during the acidification stage of fermentation, 1.76-fold greater as compared to individual substrate. Hydrolysis and acidification yields were observed to be $625 \mathrm{mg}$ sCOD per g BD VS and $408 \mathrm{mg}$ $\mathrm{g}^{-1}$ BD VS respectively. More than $80 \%$ of BD carbon was recovered from OFMSW within $78 \mathrm{~h}$, out of which more than $70 \%$ was solubilized into leachate.

An approximate $55 \%$ of dissolved biodegradable organic carbon was available in the form of VFA and major composition was acetic acid and butyric acid followed by propionic acid, which could be considered as the suitable substrate for methane production via acetotrophic methanogenesis metabolic pathway. Furthermore, the leachate contains soluble part of a protein, carbohydrate and the suspended carbon, which might be further hydrolyzed during methanogenesis to enhance methane production. Kinetics of hydrolysis and acidification rate was calculated and the $k_{\mathrm{h}}$ values were noted to be $0.036 \mathrm{~h}^{-1}$ and $0.08 \mathrm{~h}^{-1}$, respectively.

\section{Conflicts of interest}

There are no conflicts to declare.

\section{Acknowledgements}

This project was supported by the National Key Technology R\&D Programs (No. 2014BAC02B02) and the State Natural Sciences Foundation of China (No. 51478240).

\section{References}

1 L. Mu, L. Zhang, K. Zhu, J. Ma and A. Li, Bioresour. Technol., 2018, 247, 103-115.

2 Y. Li, Y. Jin, A. Borrion, H. Li and J. Li, Bioresour. Technol., 2017, 243, 836-845. 
3 H. Zhou, A. Meng, Y. Long, Q. Li and Y. Zhang, Renewable Sustainable Energy Rev., 2014, 36, 107-122.

4 P. L. Mc Carty, Public Works, 1964, 95, 123-126.

5 C. J. Banks, M. Chesshire, S. Heaven and R. Arnold, Bioresour. Technol., 2011, 102, 612-620.

6 J. Jiang, Y. Zhang, K. Li, Q. Wang, C. Gong and M. Li, Bioresour. Technol., 2013, 143, 525-530.

7 L. Li, Y. Qin, Z. Kong, J. Wu, K. Kubota and Y. Y. Li, Sci. Total Environ., 2019, 652, 709-717.

8 X. Zheng, W. Zhou, R. Wan, J. Luo, Y. Su, H. Huang and Y. Chen, Chem. Eng. J., 2018, 344, 556-564.

9 H. Chen, H. Meng, Z. Nie and M. Zhang, Bioresour. Technol., 2013, 128, 533-538.

10 G. Strazzera, F. Battista, N. H. Garcia, N. Frison and D. Bolzonella, J. Environ. Manage., 2018, 226, 278-288.

11 J. Garcia-Aguirre, E. Aymerich, J. González-Mtnez de Goñi and M. Esteban-Gutiérrez, Bioresour. Technol., 2017, 244, 1081-1088.

12 K. Wang, J. Yin, D. Shen and N. Li, Bioresour. Technol., 2014, 161, 395-401.

13 R. Slezak, J. Grzelak, L. Krzystek and S. Ledakowicz, Waste Manag., 2017, 68, 610-617.

14 H. J. Kim, S. H. Kim, Y. G. Choi, G. D. Kim and H. Chung, J. Chem. Technol. Biotechnol., 2006, 81, 974-980.

15 L. Feng, Y. Chen and X. Zheng, Environ. Sci. Technol., 2009, 43, 4373-4380.

16 R. Rajagopal, A. Ahamed and J.-Y. Wang, Bioresour. Technol., 2014, 167, 564-568.

17 W. Guo, Q. Wu, S. Yang, H. Luo, S. Peng and N. Ren, RSC Adv., 2014, 4, 53321-53326.

18 M. He, Y. Sun, D. Zou, H. Yuan, B. Zhu, X. Li and Y. Pang, Procedia Environ. Sci., 2012, 16, 85-94.

19 J. Yu, Y. Zhao, H. Zhang, B. Hua, X. Yuan, W. Zhu, X. Wang and Z. Cui, Waste Manag., 2017, 59, 487-497.

20 S. Y. Xu, O. P. Karthikeyan, A. Selvam and J. W. C. Wong, Bioresour. Technol., 2012, 126, 425-430.

21 Q.-L. Wu, W.-Q. Guo, H.-S. Zheng, H.-C. Luo, X.-C. Feng, R.-L. Yin and N.-Q. Ren, Bioresour. Technol., 2016, 216, 653-660.

22 Q. Wu, W. Guo, S. Yang, H. Luo, S. Peng and N. Ren, RSC Adv., 2015, 5, 103876-103883.

23 S. Dechrugsa, D. Kantachote and S. Chaiprapat, Bioresour. Technol., 2013, 146, 101-108.

$24 \mathrm{~W}$. Arras, A. Hussain, R. Hausler and S. R. Guiot, Waste Manag., 2019, 87, 279-287.

25 P. S. Jagadabhi, P. Kaparaju and J. Rintala, Bioresour. Technol., 2010, 101, 2818-2824.

26 E. Dogan, T. Dunaev, T. H. Erguder and G. N. Demirer, Chemosphere, 2009, 74, 797-803.

27 B. Zhang, L.-L. Zhang, S.-C. Zhang, H.-Z. Shi and W.-M. Cai, Environ. Technol., 2005, 26, 329-340.

28 S. J. Lim, B. J. Kim, C. M. Jeong, J. dal rae Choi, Y. H. Ahn and H. N. Chang, Bioresour. Technol., 2008, 99, 7866-7874.
29 N. Liu, J. Jiang, F. Yan, Y. Xu, M. Yang, Y. Gao, A. Aihemaiti and Q. Zou, RSC Adv., 2018, 8, 10457-10464.

30 W. Li, M. A. H. Siddhu, F. R. Amin, Y. He, R. Zhang, G. Liu and C. Chen, Energy Convers. Manage., 2018, 156, 279-287.

31 H. Nishimura, L. Tan, Z.-Y. Sun, Y.-Q. Tang, K. Kida and S. Morimura, Waste Manag., 2016, 48, 644-651.

32 S. Xu, X. Kong, J. Liu, K. Zhao, G. Zhao and A. Bahdolla, Waste Manag., 2016, 58, 81-89.

33 A. Shewani, P. Horgue, S. Pommier, G. Debenest, X. Lefebvre, E. Gandon and E. Paul, Bioresour. Technol., 2015, 178, 209216.

34 APHA, Standard methods for the examination of water and wastewater, American Public Health Association, Washington, DC, 20th edn, 2005.

35 I. Angelidaki, M. Alves, D. Bolzonella, L. Borzacconi, J. L. Campos, A. J. Guwy, S. Kalyuzhnyi, P. Jenicek and J. B. van Lier, Water Sci. Technol., 2009, 59, 927-934.

36 O. H. Lowry, N. J. Rosebrough, A. L. Farr and R. J. Randall, J. Biol. Chem., 1951, 193, 265-275.

37 G. L. Miller, Anal. Chem., 1959, 31, 426-428.

38 L. Lin and X. Li, Chemosphere, 2018, 194, 692-700.

39 V. A. Vavilin, B. Fernandez, J. Palatsi and X. Flotats, Waste Manag., 2008, 28, 939-951.

40 Y. Mu, G. Wang and H.-Q. Yu, Bioresour. Technol., 2006, 97, 1302-1307.

41 J. Wang and W. Wan, Int. J. Hydrogen Energy, 2009, 34, 33133323.

42 Y. Miron, G. Zeeman, J. B. van Lier and G. Lettinga, Water Res., 2000, 34, 1705-1713.

43 F. Hawkes, R. Dinsdale, D. Hawkes and I. Hussy, Int. J. Hydrogen Energy, 2002, 27, 1339-1347.

44 V. A. Vavilin, L. Y. Lokshina, J. P. Y. Jokela and J. A. Rintala, Bioresour. Technol., 2004, 94, 69-81.

45 M. C. Tomei, C. M. Braguglia and G. Mininni, Bioresour. Technol., 2008, 99, 6119-6126.

46 M. A. Romero Aguilar, L. A. Fdez-Güelfo, C. J. Álvarez-Gallego and L. I. Romero García, Chem. Eng. J., 2013, 219, 443-449.

47 T. Warnecke and R. T. Gill, Microb. Cell Fact., 2005, 4, 25.

48 H. Shiratori, H. Ikeno, S. Ayame, N. Kataoka, A. Miya, K. Hosono, T. Beppu and K. Ueda, Appl. Environ. Microbiol., 2006, 72, 3702-3709.

49 E. Y. Park, A. Michinaka and N. Okuda, Biotechnol. Prog., 2001, 17, 379-382.

50 Y. Zhang, G. S. Caldwell, A. M. Zealand and P. J. Sallis, Biochem. Eng. J., 2019, 143, 91-100.

51 C. Rodriguez, A. Alaswad, Z. El-Hassan and A. G. Olabi, Energy, 2018, 154, 119-125.

52 Y. Chen, J. Luo, Y. Yan and L. Feng, Appl. Energy, 2013, 102, 1197-1204.

53 A. Elliston, S. R. A. Collins, C. B. Faulds, I. N. Roberts and K. W. Waldron, Appl. Biochem. Biotechnol., 2014, 172, 36213634.

$54 \mathrm{M}$. Suto and F. Tomita, Induction and catabolite repression mechanisms of cellulase in fungi, 2001, vol. 92. 